\title{
SLCE Partnering with Social Justice Collectives to Dismantle the Status Quo
}

\author{
Sarah Augustine \\ Dispute Resolution Center of Yakima \\ and Kittitas Counties, Heritage University
}

\author{
Daniela Lopez \\ The Bus Federation
}

\author{
Harold McNaron Elizabeth Starke Brian Van Gundy \\ Lewis \& Clark College
}

\begin{abstract}
"Service-learning" is a multilayered term with a complex historical evolution. The movement traces back to the work of Robert Sigmon and the Southern Regional Education Board in the early 1970s, when it focused on building democratic communities through a combination of meaningful service and deep collaboration. As noted in Zlotkowski's 1995 essay that asked whether service-learning had a future, there came a time in the history of the movement when some of its thought leaders urgently called attention to the necessity for a more academic and scholarly focus. In the last two decades, service-learning and community engagement (SLCE) have flourished in higher education as staff, faculty, and students have realized it can be a high-impact teaching and learning practice to promote student learning and development.
\end{abstract}

While many SLCE courses and projects adopt this student focus in undertaking and reflecting upon useful service activities with community organizations, it can be difficult to implement them in ways that explicitly engage with the historical and contemporary systems of oppression - such as racism, classism, and sexism - that created the need for SLCE efforts in the first place. Tania Mitchell (2008), in fact, proposed a distinction between "traditional" and "critical" service-learning and suggested that the movement must focus on the latter and thereby challenge the foundational systems that uphold an inequitable status quo rather than risk perpetuating oppression through the former. Over the last decade, several other scholars and practitioners have called for a transformation of SLCE toward a practice aligned with social justice goals. Our own unit, the Office of Student Leadership and Service (SLS) at Lewis \& Clark College, is moving in this direction with our co-curricular SLCE programs, using the framework of critical service-learning as a guide.

Our vision for the future is a radical re-centering of SLCE within social justice collectives (SJCs), such as the organizers of the Movement for Black Lives, led by people from marginalized groups and addressing the systems of oppression most relevant to their own lives. SJCs may be registered nonprofits or non-governmental organizations but are more often, in our experience, unincorporated collaboratives comprised of individuals and groups united around a specific social justice cause. As it has been our experience that SLCE practitioners often rely heavily on nonprofit and school partners to determine the nature of SLCE projects, we are proposing a shift from individual partner organizations to SJCs so that each SLCE effort is firmly situated within a community-verified justice effort. Within this new structure for SLCE, colleges and universities, along with other stakeholders/partners, would follow the leadership of these off-campus collectives working on the frontlines of social justice movements.

For this to happen, SLCE practitioners and scholars must first acknowledge the ways in which institutions of higher education can and do perpetuate injustice. Brown University's Steering Committee on Slavery and Justice serves as a powerful example of an institution grappling with the harm it has caused and directing resources to partnership efforts that restore community. After such an honest accounting, the calls of local, national, and international movements for justice can be better heard and heeded. Once SJCs and SLCE practitioners are communicating and collaborating, pilot projects can be pursued and partnership agreements drafted around the priorities of social justice movements and the marginalized communities leading them.

\section{SLCE for Social Justice}

Mitchell (2008) provides a useful framework for designing SLCE toward social justice ends, which we understand to relate to both (a) the end goal of resource distribution and access allowing for ev- 
eryone to not only survive, but also thrive, and (b) the democratic, equitable processes in pursuit of that goal (Bell, 1997). She proposes naming social justice as the primary goal of SLCE and pursuing that goal via the redistribution of power within and through authentic relationships between stakeholder groups (such as nonprofits, schools, students); and she highlights the potential for SLCE not oriented this way to do more harm than good in communities.

In light of these concerns we believe that SLCE may be more successful at accomplishing goals related to social justice if it were decentralized from the collegiate context and re-centered within SJCs. If social justice, which includes an honest attempt to redistribute power and resources toward a fairer community and world, is the desired, end and if such power redistribution is to be integrated within the SLCE process, how might the role of the academy be shifted to make way for and, indeed, foster this change?

To be clear, we do not advocate for institutions of higher education to stop encouraging and providing resources for SLCE. Rather, we propose that the academy do a more honest accounting of its own assets and challenges, and then, following the direction of social movement leaders, find generative ways to engage that yield more (SJC-defined) progress and less (SJC-defined) harm. For instance, law schools often have faculty, clinics, and students providing vital information to SJC leaders about legal concerns related to doing social justice work. As most colleges and universities are nonprofit entities or affiliated with supportive foundations, they may be able to enhance the access of SJCs to governmental and private funding (given that SJCs are generally unincorporated and thus often ineligible to apply directly). While some institutions may already be engaging with SJCs in these ways, we are advocating for a shift in which (a) community partners consist primarily of grassroots social movement leaders from marginalized social groups; (b) academic liaisons follow the lead of those partners, rather than initiating projects themselves or foregrounding their goals for student learning and research; and, (c) a critical equity lens be utilized to assess power dynamics within and outside of community-campus partnerships on an ongoing basis so that harm is reduced and progress made.

Most U.S. colleges and universities promote ideals of democratic and engaged citizenship, as do many around the world. Some direct resources toward departments that provide learning opportunities around those ideals. We recognize this development as commendable progress and as an opportunity to evaluate the effectiveness of the re- sulting SLCE programs in reaching and sustaining SJC-identified goals. Such goals may include the elimination of racial disparities in quality of life (as evidenced in data) or the reduction of gender disparities within science and technology-related industries.

This orientation requires an acknowledgement of the ways in which institutions of higher education create barriers to justice-oriented work but also of the ways in which they create opportunities for students, faculty, and staff to critically engage with democracy and community. Campus units such as our Office of Student Leadership and Service can develop and use intentional practices in attempts to de-center the institution and align our work with SJCs. Operating under the Dean of Students' purview, our SLS office organizes co-curricular service-learning projects and programs; we believe much of our proposal is equally relevant to curricular service-learning.

\section{Social Justice and Neoliberalism}

Neoliberalism in higher education has been a confounding factor in the SLCE movement for some time (Blosser, 2016). Neoliberalism refers to the intentional political embedding of marketbased values within all aspects of our society in order to facilitate the growth of American capitalism (Harvey, 2007). As neoliberal power brokers reduce funding for education, institutions must rely on profit-generating initiatives (such as raising tuition and overloading faculty) to survive. These moves, in turn, limit access for low-wealth students, perpetuating unjust class-based and intersecting systems of oppression. Those students who do gain access to higher education are likely to encounter curricula designed to produce workers rather than critical thinkers effecting change within a democracy (Giroux, 2010). In our experience, this neoliberal context complicates and suppresses the implementation of critical SLCE, as social justice goals relate to correcting the harmful disparities of capitalism rather than further investing in systems of oppression - economic and otherwise.

SLCE can all too easily bolster these norms, as when it fails to challenge - or even encourages deficit-based views of marginalized social groups, thereby reinforcing existing hierarchies and generally effecting little change other than in students' own self-concepts (and at that, not always in a positive direction). Practitioners and other stakeholders who seek to align their SLCE practice with SJCs must struggle against both the dominant culture at most institutions and the prevailing tradition of status-blind or student-centered SLCE that is pri- 
marily, if not exclusively, concerned with student learning outcomes. Drawing on our own experience with co-curricular SLCE in the SLS office, where we have only begun to pursue a SJC-centered model, we offer the following three principles to counter these regressive tendencies and to bring about a more "critical" approach to SLCE as justiceoriented work.

\section{Principle \#1: Sustained, Layered Engagement}

The first principle we find essential to this social justice mission is the creation of partnerships sustained over time via multiple layers and rolling entry points. While course-based SLCE tends to have a fixed beginning and ending that aligns with the length of the term, quarter, or semester (unless it is designed at the level of the curriculum, to be integrated across courses and semesters, which is much less common), co-curricular SLCE is less constrained by the academic calendar. Our SLS office maintains multi-year partnerships with community organizations focused on educational disparities, generational trauma within the Native American community, environmental degradation, ableism, and housing injustice. While the partnerships continue year-to-year, our office signs semester or annual partnership agreements to clarify commitments and set attainable short-term goals, which tend to shift based on the political climate, individual stakeholders' preferences, and other factors. The partnership agreements also provide us with an opportunity to clarify our social justice frame so that primary stakeholders can also apply that frame when organizing and implementing our shared SLCE initiatives.

As some of our community partners have a variety of engagement opportunities for students (e.g. weekly projects, sporadic facilities upkeep efforts, advocacy campaigns), SLS staff deepen our engagement with these partners via multiple programs - potentially connecting them with different segments of our student population. The example of our partnership with Operation Nightwatch (a hospitality ministry for low-wealth and houseless Portlanders) provides an illustration. Agency representatives regularly participate in our annual community partner appreciation breakfast; incoming first-year students work with this organization when they come to campus prior to their first semester as a way to begin getting to know the community through activities related to economic and housing justice (our New Student Trips); organizational representatives come to campus to lead information sessions about the nature of their work and how students can get involved; current students partner with the organization during our in-town alternative spring break (ASB) trip; and others connect with the organization during monthly servicelearning projects throughout the year. Our layered, decades-long partnership with Operation Nightwatch has seen such successes as the organization receiving semester student volunteers who build relationships with hospitality center guests as well as interns; the organization receiving donations of feminine hygiene supplies after staff relayed this need to students; and the organization gaining at least one new board member as a result of a student's sustained volunteer engagement. In addition to these organizational outcomes, this partnership has also sparked students' interest in socially-just career paths and fields of study, as we have seen student participants change their postgraduate plans to better align with their new-found equity frameworks.

While these sustained and layered practices have helped to deepen SLS' commitment to our community partners, it is important to note that few, if any, of these organizations constitute the sort of SJC leadership we advocate SLCE following. Our office is still working on forming sustained partnerships with community members who live and work at the center of Portland's movements for racial justice, environmental justice, and educational equity.

Moreover, the sustained engagement for which we advocate may be further complicated by decentering the academy. As many SLCE partnerships are sustained by recruiting participants within a new class of incoming students each year, how might an SJC-centered SLCE affect access to those students? If access is reduced, which off-campus structures might be utilized to sustain engagement over time? We would recommend SLCE practitioners explore their own local extra-institutional service and learning projects, gathering localized success stories about sustained engagement within faith-based communities, radical political collectives, and non-academic volunteer programs.

\section{Principle \#2: SLCE Participants as Authors of their Own Experience}

Co-author Elizabeth (Liz), a graduate student at Lewis \& Clark College, recently served as advisor to SLS' in-town ASB trip; her main role was to provide students with guidance through a critical SLCE lens. The six student participants met together for a month to plan their engagement with the local Portland community around issues of economic injustice. By taking the lead in researching timely social issues, identifying partner organizations, and confirming logistics, students were able to pursue 
the economic justice issues in which they were most interested and bring more passion to their SLCE experiences.

However, it is important to note some tension on this point: Does shifting power from staff or graduate students to undergraduates truly build the kinds of equity we mentioned above or does it only further support traditional power relationships with communities? While students tend to wield less power than staff and faculty in academic institutions, they may still maintain a great deal of educational privilege and access to resources wholly inaccessible to some community partner organizations and other off-campus stakeholders. Thus, we acknowledge the potential for a power shift toward students to be both liberatory and oppressive. Hopefully, coupling this move with principled advising and a planning process centered within a SJC can better align with social justice goals and spark student interest in equitable power analyses while also ensuring students' enthusiastic engagement in the projects they have chosen to organize for themselves and their peers.

\section{Principle \#3: Nurturing Community- Centered Programs}

The SLS office has only begun to explore how we might enact this principle. However, during his graduate studies at Portland State University, co-author Harold organized a community-based SLCE program called, "Let's Get Our Hands On Some Racial Justice." Utilizing Mitchell's critical service-learning framework (2008), intergroup dialogue techniques, and a recent report on Portland's racial disparities produced by Ann Curry-Stevens and The Coalition of Communities of Color (http:// pdxscholar.library.pdx.edu/cgi/viewcontent.cgi?ar ticle $=1091 \&$ context=socwork_fac), Harold codeveloped curricular materials in partnership with Hands On Greater Portland staffer Melia Tichenor and Donna Maxey, founder of the communitybased dialogue program Race Talks.

Drawing from their prior experiences in community-based race dialogues and in SLCE projects, Melia, Donna, and Harold wrote participant learning objectives related to personal reflection and effective social action for racial justice. We organized four service projects with local racial justice organizations along with corresponding reflection and dialogue sessions. To recruit participants, we utilized Race Talks events, Hands On Greater Portland's website, a campus listserv, and our personal connections. The resulting team of participants and facilitators completed four SLCE projects benefitting the local chapters of the YWCA and Habitat for Humanity as well as Our United Villages and Wisdom of the Elders, two local people of color (POC)-led environmental justice organizations. Perhaps the most successful project was the one with Wisdom of Elders, during which executive director Rose High Bear oriented participants to her Native American-serving organization, which utilizes trauma-informed practices to heal generational wounds in the Native community while reinstating traditional farming and gardening practices with the help of volunteers. She also served alongside our group, engaging various participants in informal conversation related to racial and food justice, and she hosted our group's postproject dialogue on her organization's property.

While working with community-centered programs may move our SLCE efforts closer to social justice goals, it is necessary to acknowledge that the success of such engagement depends on partnering with organizations that SJCs deem legitimate. As nonprofit organizations exist within the aforementioned neoliberal system, sometimes they define success according to profit generation. Yet, the justice objectives for which we advocate are rarely valued within the market system. Thus, working with market-oriented nonprofit organizations could inhibit SLCE practitioners' relationship development work with those activists pursuing justice by disrupting market forces.

To address the aforementioned concerns related to pervasive neoliberalism, we recognize that social movement leaders and collectives also exist within neoliberal contexts. Moreover, due to their antagonistic stance with neoliberal politics, social movement leaders perhaps bare the brunt of the status quo's negative effects. It is perhaps because of this fact that social justice movements prove to be especially resilient, developing micro-communities that utilize consensus decision-making, prioritize marginalized stories and wisdom, and generally subvert oppressive power structures. While neoliberal pressures are definitely present within the social movement context, SLCE practitioners have much to gain from justice movements' liberatory resiliency.

Our stated aim is to engage social justice in a true sense, with SJCs identifying projects and outcomes based on community interests and critical equity serving as the lens through which power in relationships is constantly assessed. In practice, we seek to counter norms that favor inequality or reinforce deficit-based views cultivated by the societal context of neoliberalism, which is shared by the academy. We recommend nurturing sustained, layered engagement with community partners, selfdetermination of student participants, and building 
SJC-centered programs. While these principles help us approach critical SLCE, in part due to decentralization, these concepts and practices are in a formative stage of development, at least in our own experience. Many challenges remain in articulating practical mechanisms. How will SLCE relationships look as staffs change within partner organizations or on campus? How do we ground these values institutionally and systematically, beyond islands of justice within the academy and community? These questions merit further inquiry.

\section{Conclusion}

We acknowledge that this proposal to shift the center of SLCE work to social justice collectives led by people from marginalized groups represents a fundamental reorientation of the ways in which many - perhaps most - SLCE practitioners currently operate, including, as we shared above, ourselves. Why is such a drastic change called for? Because our communities need social justice. The limitations of a higher education-centered SLCE prohibit our collective liberation. For SLCE to address the root causes of injustice, our practice must be fully embedded within social justice collectives - envisioning and enacting new ways of knowing and doing beyond the neoliberal status quo. We entreat you: Join us in exploring a SJC-centered SLCE that follows the lead of those intersectional people of color-led, women-led, transgender-led, working-class-led and other marginalized groupled collectives working for justice and liberation.

\section{References}

Bell, L. A. (1997). Theoretical foundations for social justice education. In M. Adams, L. A. Bell, P. Griffin (Eds.), Teaching for diversity and social justice: $A$ sourcebook (pp. 3-15). New York: Routledge.

Blosser, J. (2016). Resisting the siren song: Charting a course for justice. Michigan Journal of Community Service Learning, 23(1), 102-106.

Giroux, H. A. (2010). Bare pedagogy and the scourge of neoliberalism: Rethinking higher education as a democratic public sphere. The Educational Forum, 74(3), 184-196.

Harvey, D. (2007). A brief history of neoliberalism. Oxford: Oxford University Press.

Mitchell, Tania D. (2008). Traditional vs. critical servicelearning: Engaging the literature to differentiate two models. Michigan Journal of Community Service Learning, 14(2), 50-65.
Authors

SARAH AUGUSTINE (Augustine_S@ @eritage. edu) is the executive director of the Dispute Resolution Center of Yakima and Kittitas Counties in the state of Washington and an adjunct professor of Sociology at Heritage University since 2011. Her academic work focuses on community engagement in health decision-making and human rights. She is also the co-founder of Suriname Indigenous Health Fund (SIHF), where she has advocated for Indigenous Peoples whose health and communities are threatened by resource extraction since 2004 .

DANIELA LOPEZ (daniela@busfederation. com) is a recent graduate of Lewis \& Clark College where she worked at the Student Leadership and Service Office leading service-learning trips and developing programming. Post graduation, she stepped into civic engagement work as a program and communications coordinator at the Alliance for Youth Organizing - a national network of progressive and youth-focused, grass-root organizations. Outside of her work, Daniela finds community in dancing and trying new food carts in Portland, Oregon.

HAROLD MCNARON (haroldmcnaron@ lclark. edu) serves as the director of Student Leadership and Service at Lewis \& Clark College in Portland, Oregon. With a passion for social justice, Harold enjoys opportunities to engage with students, nonprofit partners, and other community stakeholders in meaningful dialogue and other liberatory work. To meet the challenges of this work, Harold reenergizes via delicious meals with friends and the music of John \& Alice Coltrane.

ELIZABETH STARKE (estarke@1clark.edu) is a graduate student in the Student Affairs Administration MA program at Lewis \& Clark College as well as a graduate assistant to the office of Student Rights \& Responsibilities. Elizabeth is a lifelong service-learner, and her research interests center around education as a tool toward greater social justice. In her free time, Elizabeth enjoys gardening, sharing food with her community, and hiking with her dogs.

BRIAN VAN GUNDY (bvangundy @ lclark.edu) is a graduate student in the Student Affairs Administration MA program at Lewis \& Clark College as well as a graduate assistant in the Student Leadership and Service office. A first generation student, Brian's scholarship and practice is focused on increasing access to higher education among students from marginalized communities. 